\title{
AN INTRODUCTION TO BISHOP BERKELEY'S THEORY OF VISION*
}

BY

\author{
MiCHAEL MURRAY
}

EDINBURGH

George Berkeley, one of the geniuses of his age, was born in the County of Kilkenny, in 1685. His father is reported to have been a captain of horse and his moth'r is believed to have been a great-aunt of General Wolfe, the hero of Quebec.

Having distinguished himself at school,. Berkeley entered - Trinity College, Dublin, in his fifteenth year.

- It is related that many of his fellow students regarded him as a fool and made fun of his eccentricities, but those who knew him - well recognised some of the deep learning and originality which was later to make him world famous.

His Theory of Vision which is the subject of the present paper, was published in 1709. His treatise on the Principles of Human Knowledge appeared in the following year. The two works formed the basis of his famous Philosophy of Idealism.

Berkeley's life was, on the whole, an active one and was certainly not devoted to theorising.

He travelled extensively on the Continent and was at one time the chaplain and secretary of the English ambassador to the Italian States.

Among his friends and admirers could be mentioned Pope, Steele and Dean Swift, and not long after his return from Europe, the Duke of Grafton appointed him to the deanery of Derry. "It soon became apparent, however, that this benevolent philosopher was not interested in church-preferment.

He had long been cherishing a scheme for founding a college . in the Bermudas, for the purpose of educating the American Indians and converting them to Christianity.

Undaunted by difficulties, his enthusiasm raised him a small band of followers and a promise of financial help from the Govern- ment. He sailed for Rhode Island in 1728; but the promised funds were never paid and he was forced to abandon the scheme after several years. His affairs, improved, however; and in 1734 he was appointed Bishop of Cloyne.

The last years of his life were spent at Oxford: dying in 1753, he was buried in Christ Church.

Among his works is included a latin treatise on mathematics, an essay on the famous South Sea Bubble, and a tract on the medicinal properties of tar-water.

The Theory of Vision is a psychological study, and is the first 
attempt to distinguish purely visual sensations from those in which sight is aided by the other senses. The essay is in advance of the age in which it was written, and it has been pointed out that it could have been the work of a disciple of Helmholtz.

Space forbids a reproduction of it in full, but the following is a précis, which, it is hoped, will do justice to the main arguments contained in the original.

\section{The Theory}

It is generally agreed that distance by itself cannot actually be seen. For distance is a line the end of which focuses at a point on the fundus, which point remains unaltered whether the distance is great or small.

In estimating the distances of far away objects, we have to rely on previous experience and we are aided in our judgment by considerations of size and aerial perspective and other signs which we have been taught-to acknowledge. If we had not had previous acquaintance of these signs, we would have no conception of remote distances.

In dealing with near distances, it is 'popularly supposed that one judges distances by the optic axes of the eyes which form an angle at the object : accorring as to whether this angle is great or small; do we judge whether the object is far or near.

For close objects there appears to be some very necessary connection between these optical angles and our distance judgments. It would appear, therefore, that in this case, we are not dependent on experience and that anyone could judge the proximity of an object, purely by the degree of angle formed by the concurrence of his optic axes.

When using only one eye, the size of the pupil varies with the divergency of the light rays which issue from the object and fall on the eye, the point being judged nearest which is seen by the most divergent rays. Similarly, it does not seem to require experience to tell us that the more parallel the light falling on the eye, the further off is the point from which it emanates.

Although the above arguments are currently accepted as, true explanations of our methods of judging distances, they are unsatisfactory for the following reasons.

In the first place, when the mind does not perceive an idea directly it must do it through the medium of some other idea.

For example, we cannot see the feelings in a man's mind, but we can perceive them by the colours they produce in his face. One often sees shame or fear in the looks of a man by watching his face turn red or pale.

Moreover, it is obvious that no idea which is not of itself perceived can be the means of perceiving another idea. If I do not 
see a man's face turn red, I cannot detect the presence of shame in his mind.

Now, as was stated at the beginning, distance is by itself imperceptible, and yet it is perceived by sight; it must, therefore, be brought into view by some idea which is immediately perceived.

Firstly, it must be admitted that those angles and lines by which some men attempt to explain the perception of distance, are not seen'themselves : in fact, they are not considered by those ignorant of optics. Since these lines and angles are "not themselves perceived by sight, the mind cannot by them judge the distance of objects.

. Secondly, these lines and angles have no real existence, being a mathematical hypothesis introduced into optics in order that the science may be treated in a geometrical way.

Now, it has already been shown that distance must be suggèsted to the mind through the mediation of some other idea ; it remains to be shown what these ideas are.

Experience teaches us that when we look at a near object with both eyes, we alter the disposition of our eyes by lessening or widening the distance between the pupils. This turning in of the eyes is accompanied by a sensation which introduces the idea of greater or less distance into the mind.

(" This 'sensation' of organic change in the eye is, of course, not seen. It belongs to our tactual experience in Berkeley's wide meaning of 'touch.' It may be called visual but not visible.') ${ }^{1}$

Now there is no fundamental or necessary connection between the sensations attending the turning in of the eyes and greater or less distance. It is merely that an habitual or customary connection has grown up between these two sorts of ideas. So that the mind no sooner perceives the sensation arising from the different turning in of the eyes, than it immediately perceives the different idea of distances which it is accustomed to associate with that sensation. Similarly on hearing a certain sound, the idea which custom has united with it is immediately suggested to the mind.

From which it follows that the judgment we make of the distance of an object is entirely the result of experience. If we had not repeatedly associated certain sensations arising from different dispesitions of the eyes, attending different degrees of distance, we would never be able to make sudden judgments of distance, any more than we could judge a man's thoughts by his pronouncing words which we have never heard before.

In dealing with one eye, if the object is brought very near, it becomes confused, in- which case we associate a greater degree of confusion with proximity. It is true that we may prevent the 
appearance of the object growing more confused by straining the eye, in which case the sensation of strain supplies the place of confused vision and aids the eye in its judgment.

In neither case, however, does the mind judge the distance by the greater or less divergence of the light rays, but depends upon the arbitrary signs of either confusion or strain.

From what has been stated, it follows that a man born blind, being made to see, would at first have no idea of distance by sight. The sun and stars, together with near objects would all seem to be in his eyes or rather in his mind. In fact all objects would seem to him as' near as pain or pleasure or the innermost feeling of his soul.

If, as is commonly supposed, men judge distance by the angles of the optic axes, then a blind man gaining his sight would require no new experience to perceive distance by means of his vision.

Now it is agreed that colours are the immediate objects of sight and that they are inside the mind and not outside it. Yet what do we mean by the terms extension, shape and motion? If we consider the matter, we are forced to the conclusion that we cannot conceive extension without colour, nor can we conceive shape and motion without extension.

Suppose, for example, I am looking at the moon which I judge to be 240,000 miles away. I see a small round luminous flat, but it is quite clear that the real moon is nothing like that. If I was carried towards the moon, the visual impression would change so much on approach that the original impression would be entirely lost.

Again, suppose I see in the distance a faint outline of something which I take to be a man, tree, or tower and judge it to be a mile off. It is obvious that what I see is not a mile off, since every step I take alters my impression of it.

The truth of the matter is, that having for a long time experienced certain ideas such, as distance, shape, and solidity by touch and connected them with certain ideas of sight, 'I do, upon' perceiving these ideas of sight, automatically conclude the tangible ideas which usually follow.

("This is the first distinct mention of 'touch' in the Essay a term which with Berkeley includes not merely the organic sense of simple contact, but also the sense of muscular resistance, and the sensations due to our locomotor activity. From this point he begins gradually to unfold the antithesis of the visible and the tangible worlds - of coloured and resistant extension. To explain by suggestion and habit the synthesis of these antithetical elements is the aim of his theory." ')

From what has been said, it follows that neither distance nor things placed at a distance are truly perceived by sight. They are no more perceived by the eye than they are by the ear. 
Sitting in my study I hear a coach drive up the street, I look through the window and see it, then walk out and enter into it. In common language one speaks as if one heard, saw, and touched the same thing, namely, the coach. But in actual fact the ideas sent into the three senses are widely different and distinct from one another. It is only because they have been so often associated, that one imagines them to be one and the same thing.

It requires some thought to arrive at this conclusion, but if you examine the matter closely you will understand that you never hear, feel and see the same thing. What is seen is one thing, and what is felt or heard is another. This point is difficult to grasp because visible and tangible ideas are given the same name. The whole ùse and purpose of language makes this a necessity.

In order to understand accurately the process of vision, one must bear in mind that there are two sorts of objects-primary, and secondary. Primary visual objects are inside the mind. They can become big, small, faint or clear, but they cannot approach or recede from us. But when we speak of an object coming near or drawing away, we are referring to a secondary object. These objects are not so much seen by the eye as suggested to the eye in the same way as thoughts are perceived by the ear. To give an example : no sooner do we hear the words of a familiar language than we immediately think the thoughts that they represent and we act as if we heard the very thoughts themselves.

In the same manner, secondary objects, or those which are only suggested by sight, often impress us more strongly than the proper objects of sight along with which they enter into the mind and with which they have a far stricter connection than ideas with words.

The above in outline constitutes the first part of the theory. The remainder of the essay treats in a similar fashion our estimation of size. He explains that geometry deals with tangible extension and not visible extension, and the whole leads up to his theory of a divine visual language.

However, sufficient has been given to illustrate the trend of his arguments. It is outside the scope of the present paper to discuss any of the premises or arguments round which the theory is built, and the discussion which follows deals purely with the main - conclusions.

Berkeley was an empiricist, the term implying that space perception is entirely learnt as against it being inherited or instinctive.

He has also been described as a tactualist, which term suggests better his doctrine that touch is the space sense par excellence, and that sight in its primitive purity is devoid of all space character. Furthermore, he argues that sight and touch are two entirely 
independent sources of information. Impressions received from one source cannot be appreciated in terms of the other, without their having been previously experienced in association. Colours are the only direct sensations which the eye can appreciate. Space means room to move about in. When one sees an object six feet away one judges this distance purely in the amount of locomotor activity which one would require to cover the ground in order to reach it. Previous education has taught us to associate our tactile experiences so intimately with certain visual signs that we imagine these visual signs give us first hand information of the extended world. The statement "I see distance" is, as Hollingworth puts it, analogous to the statement " the water looks cold."

This was the doctrine introduced by Berkeley. The vista of speculation which it opened up formed a background for a controversy which involved many future generations of authorities on visual optics. They were divided roughly into two schoolsthe empiricists, of which Helmholtz and Wundt were notable examples, and the nativists which included Hering and Muller. The nativists believe in the inheritance theory and long are the arguments which raged-round the well-known query which was put to Locke 4 in a letter from Molyneux. The question asked whether a man born blind being made to see would be able to distinguish a cube from a sphere although previously acquainted with them only with his hands?

The answer is one which should be decided by experiment, and Berkeley in his original essay quotes no evidence of this kind.

However, in the "theory of Visual Language Vindicated and Explained," published in 1733, he cites the famous operation of Cheselden. ${ }^{5}$ The patient, $a$ boy of fourteen, was suffering from dense congenital cataract which was successfully couched. "When he first saw, he was far from making any judgments about distances, that he thought all objects whatever touched his eyes." "He knew not the shape of anything nor of any one thing from an other."

Since then there have been a number of these cases on record, but they belong for the most part to the nineteenth century. More modern instances are rare, owing to the fact that such cases rarely escape.being treated in early childhood.

But the- reports as they stand are more or less in accordance with Cheselden's observations, and of Raehlmann's ${ }^{6}$ case it is recorded that the patient failed to recognise familiar objects such as a cup, and on seeing a large bottle for the first time, thought it was a horse.

The following is quoted from a case given by Nunneley. ${ }^{7}$ The patient, a highly intelligent boy aged nine, was acquainted with a sphere and a cube, prior to his operation. After the operation 
he was confined to a dark room. After keeping him in a dark room for a few days, until the opaque particles of his lenses were nearly absorbed, and the eyes clear, the same objects which had been carefully kept from him, were again presented to his notice. $\mathrm{He}$ could at once perceive a difference in their shape though he could not in the least say which was the cube and which was the sphere. "He said everything touched his eyes, and walked most carefully about, with his hands held out before him, to prevent things hurting his eyes by touching them.".

The account of Franz ${ }^{\prime} s^{8}$ case strikes a different note. The patient, a youth of eighteen, could distinguish bright colours - before he was operated on,-but he had no form sense. After his operation he was able to distinguish between 'the position of a' vertical and a horizontal line. He could also determine a circle, a square, and a triangle, and name them as such, saying that he could only do so when he imagined the tips of his fingers feeling the objects. Solid objects he judged to be flat, and he could not distinguish between an object floating on the top of a glass of water and one at the bottom. The human face appeared to him às in one plane.

The case described by Latta $^{9}$ in which a thirty years old patient of Dr. Maitland Ramsay was able to distinguish the shape of a ball and a toy brick, is weakened, as the account points out, by the fact, that prior to the experiment, he may have picked up a little visual knowledge of shape from other objects.

- Fisher's ${ }^{10}$. case, which is the most recent account the writer has read, is disappointing as the details given are too meagre. Here it is reported that a girl in her seventh "year was operated on in St. Thomas's Hospital. Being afterwards tested she failed to describe a penny and named a pair of scissors as a piece of glass.

On first reading these cases it would seem that the experimental evidence afforded by them was in favour of the tactualists' point of view. This was the opinion held by Clarke Murray ${ }^{11}$ and others, but there are serious objections.

In the first place, a person recovering from such an eye operation is at a considerable disadvantage. $\mathrm{He}$ is probably in some degree of pain, his visual activity is low and he is dazed by the light and the novelty of the experience.

As Stratton ${ }^{12}$ points out, many people with normal sight fail to recognise objects in a bad light, or in unfamiliar surroundings, or in unusual positions. Stratton suggests a forceful illustration of the problem. Suppose someone in a dark room is groping about for a cup, and his hand passes over one, which although ordinary in shape, is made of ice or butter. The probability is that the individual would be so impressed with the slithery feel of the article that he would fail to recognise it as a cup. 
Would not this situation be analogous in some respects to that in which Raehlmann's patient found himself on being visually confronted with a cup for the first time? There is no doubt that he, in common with the other patients, did fail the tests, but the point is that the tests do not prove that they failed for the reasons Berkeley advances. For the tactualists. would have it that visual conceptions of size and shape were absolute novelties to the patients, and tre tests do not prove this.

It would appear as if the investigators expected too much, and were not concerned with primitive vision but devised tests which anticipated the vision in a partially developed state. It is now universally admitted that accurate perception of distance can only be learnt. But has it been established that we have no innate capacity for visual space perception like the one we have for colour or brightness? Can it be that experience merely organizes our judgments inside a spacial frame which is inherent at birth?

These are the questions at issue.

The fact that the patients detected a difference in shape although unable to name it, would indicate some inherent form sense, the existence of which the tactualists would not be prepared to admit. The fact that some of them said the objects touched their eyes , might be their way. of expressing that they were dazzled by the light.

Then there is Dr. Franz's case which appears to refute Berkeley's arguments. The account given is reasonably full and the tests appear to have been scientifically conducted. However, there is one point on which we would like to be better satisfied. How much light sense did the patient have prior to the operation? It is recorded that he could distinguish certain bright coloured lights. He also thought he could uistinguish the shape of very strongly illuminated patterns, but this Dr. Franz assures us, was a mere illusion.

The point raised here is one which bears on a number of con: genital cataract cures : namely, that they are not completely blind. They can usually distinguish strong light from darkness if nothing else. Parsons ${ }^{13}$ states that they can often project light impressions and can also, if sufficiently intelligent, project phosgenes caused by pressure on the eyeball; so that we can conclude that this could give them some visual experience of space prior to their operation. Moved by these considerations, we cannot accept the reports of these operations as evidence that Berkeley was wrong. Although for reasons previously stated, we cannot conclude from the evidence that Berkeley was right.

Before considering any different types of experiments, let us examine some alternative theories on space perception.

What has been described as the visualist theory was advanced by Platner and supportéd to some extent by Hamilton. ${ }^{14}$ 
As opposed to the tactualists, the visualists maintained that sight alone gives us a knowledge of space and that the congenitally blìnd live in a purely time world. There are few facts to support this view. On the contrary, Saunderson has shown us how the blind can understand geometry.

Like the tactualists, the visualists have a one-sided doctrine, although it is one which is more easy to dispose of.

Then there is the opinion that both sight and touch give us first hand information of the world of space. Granting that this is so, it remains to be demonstrated whether it is congenital or acquired. If it can be shown that the sense of sight can appreciate space instinctively then Berkeley's theory is untenable.

It is not to be expected that this instinctive visual perception of space is very great. It may be that because it is so small in its undeveloped state that the empiricists have concluded that it does not exist at all. That it does exist in lower animals has been conclusively proved. It must often have been observed that chicks peck with extraordinary accuracy almost as soon as they are out of the shell, and this fact has been scientifically established. Vernon Grant ${ }^{15}$ quotes the experiments of Lashley and Russell on the visual perception of rats.

A group of these rodents was reared in darkness for a hundred days. After which, the experiment consisted in making the hungry animals leap from a platform to another one in order to obtain foød. The first platform was specially prepared in order to measure the force of the leap in grams, the reason being that the force behind each leap would vary with the distance away from the second platform. The stage was set with the food $20 \mathrm{cms}$. away and in the first attempt, all the rats overshot the mark, but rapidly improved. Next the food was moved $40^{\circ} \mathrm{cms}$. away. This time ten out of the thirteen rats jumped with greater force than was required for the $20 \mathrm{cms}$. range. The average force exerted for the last five trials at $20 \mathrm{cms}$. being 6.8 grams, while that for the first jump at $40 \mathrm{cms}$. was 15.4 grams. The important point is that although few were able to reach the food platform at a first attempt, the greater distance immediately called for a stronger leap.

In the next test the rats' performance was nearly as good as that of a control group reared under ordinary conditions. Variations in force were noted for"distances of under $2 \mathrm{cms}$. Grant states that here an inborn judgment for distance has been demonstrated but declines to draw any conclusions concerning human vision.

However, from these and other similar experiments, we must admit the possibility, if not the probability, of a similar innate organisation existing in man. 
From observations on infants, it has been shown that they can fixate monocularly almost as soon as they are born, but more in this connection cannot be declared for certain.

In general, therefore, we sum up the existing evidence by stating it to be inconclusive and not deciding our problem one way or the other.

William James ${ }^{16}$ was opposed to the Berkeleyan theory, and held the opinion that space and voluminousness were inherent in all sensations. 'Parsons ${ }^{17}$. on the other hand holds that visual space perception, so far as magnitude is concerned, presupposes tactile or haptic perception.

Duke-Elder ${ }^{18}$ concludes that the most reasonable interpretation of the observed phenomena seems to take in both points of view. He sums up in stating that the conception of space is built up on an innate but plastic basis which is modified by experience. Just where the differentiation between the two processes takes place, is, he considers, largely a matter of individual opinion. He holds a fairly strong brief for pushing the empiricists' view on the grounds that it is the one which is more stimulating to research.

Contemporary psychologists do not debate the issue. As Vernon ${ }^{19}$ puts it "As in all our perceptions, objective stimulus conditions and subjective conditions in the individual are combined and organized to form a basis for our perceptions of space, and our ability to estimate and judge extent." What appears to them to be more important, is to investigate the relationship between the various perceptual patterns which subserve space perception.

\section{Appendix}

The experiments of Stratton threw some interesting light on the spacial relationship between sight and touch. In practice we see an object where we touch it. For example, an article touching the skin is seen lying against it, whilst one at arm's length is seen about two feet away, etc.

The question raised is whether there is any point in the visual field where we can say we should see something we happen to be touching. Was there a time when such experiences were unconnected? Was there a time when the visual sensation of an object and the pressure on the hand that grasped it were not localized at the same poînt in space?

The experiment where Stratton wore an inverting lens system until his mind learnt to compensate for it, is well known. $\dagger$ But hís more elaborate and no less interesting experiment with mirrors is not frequently referred to. The following is a brief account.*

$\dagger$ Details given in the Psychological Reveiw, Vols. III and IV.

*For full account see "The Special Harmony of Sight and Touch," Mind, October, 1899. 
He attached to himself a pair of mirrors by means of a light frame, so that he observed himself from a point above his own head.

In the diagram, $\mathrm{AB}$ represents a horizontal plane mirror while $\mathrm{C}$ is a smaller mirror fixed at an angle of 45 degrees. $\mathrm{BD}$ is - a dark cloth screen which was fastened round sufficient of $A B$ to - exclude any peripheral vision.- DE is the image of the observer. The arrangement enabled him to see the whole of his body plus a small radius round about it.

On the first day the apparatus was worn from 3.20 p.m. to 9.30 p.m.: on the second day from 9.0 a.m. to 7.30 p.m., and on the third day from 9.45 a.m. to 5.15 p.m. In between times the eyes were securely blindfolded.

Naturally to begin with there. was constant rivalry between the spacial reports of the two senses. The body and limbs were seen at different places from where they were felt. Not only were the visual images out of direction, but they were also at misleading distances, so that the whole co-ordination between sight and touch were disrupted.

However, on the third day Stratton reports that he was beginning to get used to the situation, and there were occasions when he felt his body in the same place where he saw it. By the end

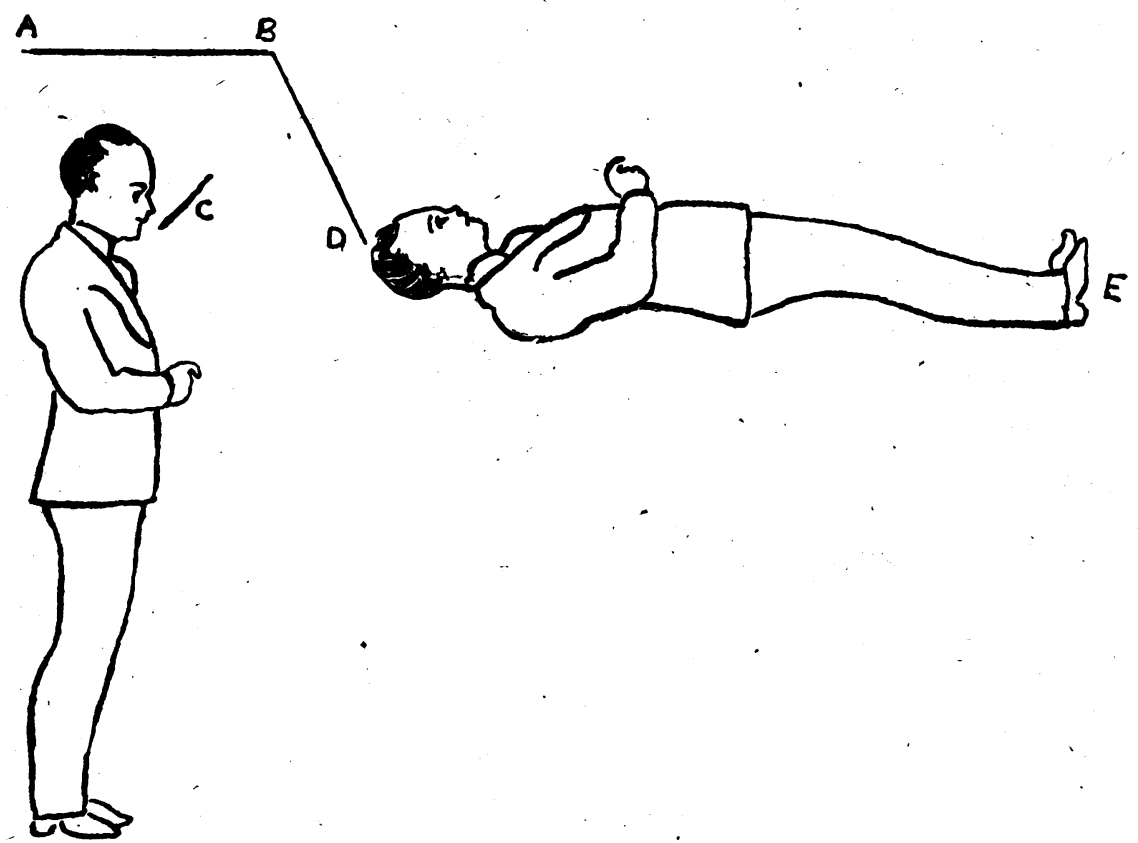

Stratton's mirror device for showing the body in a false direction and distance. 
of the third day he had experimented sufficiently to be convinced that we have only to see a thing for long enough in a given place to imagine we feel it there also. He concludes that if we had been so constructed that we always saw our bodies a hundred yards away we would feel them there also. In fact a spacial harmony between the two senses can grow up under a vast variety of conditions, provided that the experience be sufficiently uniform. From his results, it appears likely that normal reactions are developed in a similar way. But this fact does not alter the conclusions arrived at in the paper.

One must be cautious about applying conclusions drawn from an experiment dealing with reactions, to a. problem dealing with origins.

\title{
REFERENCES
}

1. Fraser.- “ Selections from Berkeley," p. 135, 1874.

2. Fraser. - Op. Cit., p. 142.

3. Quoted from-GRANT.-Psychological Optics, p. 116, 1938

4. ALCKE.-Essay on the Understanding, Bk. II, Cap. IX, 1690.

5. Philosophical Transactions, 1728.

6. Raehlmann.-Zsch.f. Psych. u. Physiol. d. Sinnesorg, 1891.

7. NUNNELEY.-Organs of Vision, pp. 30-33, 1858.

8. Franz.-Philosophical Transactions, 1841.'

9. LatTa.-Brit. Jl. of Psychól., Vol. I, 1905.

10. Fisher.-Ophthal. Rev., 1914.

11. Clarke MURRAY.-Hand Book of Psychology, p. 170, 1892.

12. Stratton.-Experimental Psychology, p. $131 \mathrm{ff}, 1903$.

13. Parsons.-Introduction to the Theory of Visual Perception, p. $157 \mathrm{ff}$.

14. Hamilton, W.-Léctures on Metaphysics, Vol. II, xxviii, 1858.

15. Grant. Op. Cit., p. 118.

16. JAMES, W.-Principles of Psychology, Vol. II, Chap. XX, 1890.

17. Parsons.-Op. Cit.

18. DUKE-ELDER.-Text-Book of Ophthalmology, Vol. I, p. 1060.

19. VERNON.-Visual Perception, p. 64, 1937.

\section{THE EFFECT OF THE DURATION OF STIMULUS ON THRESHOLD MEASUREMENTS IN THE DARK ADAPTED EYE**}

\author{
BY V,
}

Simon YudKIN, Ph.D., M.B., M.R.C.P., Flight-Lieut., R.A.F.v.R. FROM R.A.F. INSTITUTE OF PATHOLOGY AND TROPICAL MEDICINE

\section{Intfoduction}

INSTRUMENTS used for the determination of dark adapted rod thresholds incorporate a test light which is either continuously illuminated (Craik \& Vernon, 1941, S. Yudkin, 1941) or exposed as a flash of definite duration. The duration of flash used in the latter type of instrument varies, however; for example, Wald and

\footnotetext{
* Received for publication, August 22, 1944.
} 